\title{
Lifestyle Factors Associated With Undernutrition in Older People After the Great East Japan Earthquake. A Prospective Study
}

Kanako Okazaki ( $\sim$ kana-oka@fmu.ac.jp)

Department and Institution address:1-Hikarigaoka, Fukushima City, Fukushima, 960-1295, Japan

Tetsuya Ohira

Department of Epidemiology, Fukushima Medical University School of Medicine

Akira Sakai

Department of Radiation Life Sciences, Fukushima Medical University School of Medicine

Michio Shimabukuro

Department of Diabetes, Endocrinology and Metabolism, Fukushima Medical University School of Medicine

\section{Junichiro Kazama}

Department of Nephrology and Hypertension, Fukushima Medical University School of Medicine

Atsushi Takahashi

Department of Gastroenterology, Fukushima Medical University School of Medicine

Hironori Nakano

Radiation Medical Science Center for the Fukushima Health Management Survey, Fukushima Medical University School of Medicine Fumikazu Hayashi

Radiation Medical Science Center for the Fukushima Health Management Survey, Fukushima Medical University School of Medicine Masanori Nagao

Radiation Medical Science Center for the Fukushima Health Management Survey, Fukushima Medical University School of Medicine Seiji Yasumura

Department of Public Health, Fukushima Medical University School of Medicine

Hitoshi Ohto

Radiation Medical Science Center for the Fukushima Health Management Survey, Fukushima Medical University School of Medicine Kenji Kamiya

Radiation Medical Science Center for the Fukushima Health Management Survey, Fukushima Medical University School of Medicine

\section{Research Article}

Keywords: Older people, Undernutrition, the Great East Japan Earthquake, Lifestyle factors, Regular exercise, Physical activity

Posted Date: December 17th, 2020

DOI: https://doi.org/10.21203/rs.3.rs-120958/v1

License: (c) (i) This work is licensed under a Creative Commons Attribution 4.0 International License. Read Full License 


\section{Abstract}

Background: The aim of this study was to conduct a longitudinal examination to assess the relationship between lifestyle habits, including exercise habits, and the incidence of undernutrition after the Great East Japan Earthquake.

Methods: We included residents aged 60 years or more who lived in the evacuation area municipalities from 2008 to 2010 before the disaster. A total of 31,411 participants $(14,350$ men and 17,061 women) who underwent a physical examination during this period were followed-up through 2017 . We estimated the associations between undernutrition after the disaster and lifestyle factors using a multivariate-adjusted analysis with a Cox proportional hazard regression model. The variables included the model were evacuation, exercise habits, meals before bedtime, history of gastrointestinal surgery, history of lifestyle-related diseases, and 2 or more subjective symptoms.

Results: In all, 1721 of the 13,378 participants were newly undernourished after the disaster. The statistically significant variables influencing the occurrence of undernutrition were non-evacuation (hazard ratio, 1.31; 95\% confidence interval 1.17-1.47), poor exercise habits ( $\mathrm{HR}, 1.14$; 95\% $\mathrm{Cl} 1.03-1.50)$, and poor physical activity (HR, 1.12; $95 \% \mathrm{Cl} 1.01-1.25)$. Other related variables were surgical history, lifestyle-related diseases, and two or more subjective symptoms. No statistically significant interactions with exercise habits were identified for each lifestyle factor.

Conclusions: These results suggest that regular exercise and/or maintaining physical activity might be important, regardless of sex, other lifestyle habits, or past medical history, in preventing undernutrition following a disaster.

\section{Introduction}

With the increasing age of the Japanese population, extending the healthy life expectancy is a challenge. $70 \%$ of men and $90 \%$ of women in older adults aged 60 years or more are less independent owing to dysfunction caused by geriatric syndrome. ${ }^{1}$ To extend the healthy life expectancy of older adults, diseases and age-related changes that lead to a decline in function need to be prevented or ameliorated. Older individuals tend to have low physical activity, decreased appetite and low nutrient intake, resulting in undernutrition and decreased muscle mass, which in turn lowers baseline metabolism and limb muscle strength, leading to decreased walking speed, greater difficulties in getting around, and lower activity, a situation known as "the frailty cycle". ${ }^{2}$ In Japan, the prevalence of undernutrition [body mass index $(\mathrm{BMI}) \leq 20.0 \mathrm{~kg} / \mathrm{m}^{2}$ ] in individuals aged 80 years was $>15 \%$ for men and $>20 \%$ for women, the main risk factor for health deterioration. ${ }^{3}$ Early detection and intervention for undernutrition and decreased activity are important for interrupting this vicious circle.

After the Great East Japan Earthquake, evacuees from the government-designated evacuation areas were forced to move and change their lifestyle behaviors, including diet, exercise, and other personal habits. Many evacuees had to change jobs, and some received inadequate health check-ups and experienced varying degrees of anxiety about their health. These changes in living environment following the disaster have resulted in increased psychological stress and decreased physical activity. ${ }^{4-8}$ According to the Fukushima Health Management Survey (FHMS) conducted in the Fukushima Prefecture after the disaster, lifestyle-related diseases were confirmed to worsen with increasing body weight. ${ }^{9-14}$ Some residents, however, lost weight and reduced their nutrition intake due to the disaster. The FHMS reported that people in the evacuation centers, temporary housing, apartments, etc. consumed less fruit and vegetables, meat, and soy and dairy products than those who lived in their own or relative's homes. ${ }^{15}$ The frailty risk is therefore expected to increase in the older evacuees owing to aging, reduced physical activity, decreased nutrient intake, and changes in living environment. ${ }^{16}$

In Japan, the frailty rate (mean age at onset, 71 years) was $11.3 \%$ according to the Cardiovascular Health Study criteria. ${ }^{17}$ The results of the analysis that integrated four representative large-scale cohort studies using this criteria in Japan showed that the prevalence of frailty in the community-dwelling older population was $7.4 \%$. The prevalence of frailty increases with age and markedly increases after 75 years of age. ${ }^{18}$ Frailty requires long-term care and is affected by the damage caused by the disaster. ${ }^{16}$ However, no study has shown the rate of frailty in the evacuation area after the disaster, the actual state of weight loss or functional decline, or the relationship between the changes in lifestyle owing to the evacuation after the disaster and frailty risk.

To examine the factors associated with the onset of undernutrition among older evacuees after a disaster, we therefore longitudinally examined the relationship between undernutrition onset and lifestyle factors such as exercise and eating behavior. We hypothesized that individuals who maintained physical activity before the disaster would have a lower undernutrition risk after the disaster.

\section{Methods}

We considered a method for screening frailty from related items using data from health examinations, a health project in which local residents had already participated.

\section{Study population}

The participants were residents aged 60 years or more living in evacuation-designated areas near the Fukushima Daiichi Nuclear Power Plant in the Fukushima Prefecture before the disaster. The evacuation area included 13 municipalities: Hirono-machi, Naraha-machi, Tomioka-machi, Kawauchi-mura, Okuma-machi, Futaba-machi, Namie-machi, Katsurao-mura, litate-mura, Kawamata-machi, Tamura City, Minami-Soma City, and Date City. Within the evacuation area, those aged 40-74 years had enrolled in national health insurance, and those aged 75 years or more had enrolled in the medical system for the elderly and underwent annual health check-ups.

Between 2008 and 2017, a total of 254,161 individuals aged 60 years or more underwent medical examinations. Of these, 68,010 examinees aged 60 years or more who underwent at least one health check-up before the disaster during 2008-2010 (baseline period) were examined. We excluded the second and 
subsequent results if there was more than one visit during this period. We therefore included 31,411 participants (14,350 men and 17,061 women; mean age, 69.8 years) who underwent a health examination during this period.

We excluded 13,789 individuals who were overweight $\left(\mathrm{BMI} \geq 25.0 \mathrm{~kg} / \mathrm{m}^{2}\right)$ or undernourished $\left(\mathrm{BMI} \leq 20.0 \mathrm{~kg} / \mathrm{m}^{2}\right)$; $17,601 \mathrm{were}$ eligible for follow-up examinations that were conducted from 2011 to 2017 . Given that 4244 participants did not undergo follow-up examinations, 13,378 (6351 men and 7027 women, $76 \%$ ) were ultimately eligible for our analysis (Fig. 1).

\section{Measurements/definitions and data collection}

The predisaster data was provided by the medical examinations conducted by municipalities and included specific health examinations and late-elderly health examinations. For the postdisaster follow-up data, we used the FHMS data and the above data collected by the municipalities. The baseline and follow-up examinations included a medical history review, physical examination, anthropometric measurements, and questionnaire regarding lifestyle behaviors.

\section{Undernutrition}

The participants' body weight and height were measured (with their shoes and excess clothing removed) on the same calibrated scale at baseline and followup. BMI was calculated as the body weight $(\mathrm{kg})$ divided by the square of the height $\left(\mathrm{m}^{2}\right)$. According to the National Health and Nutrition Survey, undernutrition was defined as a BMI $\leq 20.0 \mathrm{~kg} / \mathrm{m}^{2}$. A number of researchers recommend the use of $\mathrm{BMI}$ as an objective indicator in older individuals. ${ }^{19-21} \mathrm{BMI}$ is not a sensitive indicator in a clinical setting for indicating rigorous changes in clinical situations because individuals with a normal or high BMI can have clinically significant weight loss. Older individuals often have spinal deformity and difficulty standing; therefore, the height measurement needed to calculate BMI is unreliable. ${ }^{22}$ In this study, however, the target participant was a community-living older individual who could undergo a health check-up. A number of studies have used the BMI measured during the health check-up as an indicator of undernutrition. ${ }^{23}$ We therefore used this definition.

\section{Weight loss amount}

In previous studies, the weight loss criterion used for determining frailty was " $2-3 \mathrm{~kg}$ in 6 months.". ${ }^{24,25}$ As an "unintended sudden weight loss" for determining geriatric syndrome risk, there was the index " $5 \%$ weight loss in 6-12 months." ${ }^{26}$ However, identifying the weight loss within such a short period is difficult using the medical examination data in this study. We therefore calculated the change and rate of change throughout the observation period as follows: "weight loss ( $\geq 5 \mathrm{~kg}$ or $\geq 5 \%$ )" from baseline, "amount of weight loss, kg," "weight loss per year, kg/year," "weight loss rate (loss/weight)," and "weight loss rate per year, \%/year."

\section{Lifestyle status}

Information on lifestyle factors, such as smoking status, exercise habits, physical activities, insufficient sleep, and dietary behaviors, were obtained from a self-administered questionnaire from the standard interview items during the medical check-ups ${ }^{27}$ and were classified into two categories. Smoking status was indicated as regular smoker or nonsmoker. Insufficient sleep was defined by whether the sleep provided rest (yes/no). Dietary behaviors were defined as follows: skips breakfast (skipping breakfast more than thrice a week), meals before going to bed (having dinner within $2 \mathrm{~h}$ before going to bed at least thrice a week) and snacking after dinner (more than three snacks after dinner a week). Drinking status was indicated by the frequency of drinking and the amount of alcohol consumed per day and was categorized into three groups for the weekly alcohol intake: "Never drinks (including quitting)," "Drinks < $44 \mathrm{~g} / \mathrm{day}$," and "Drinks $>44 \mathrm{~g} /$ day". Other items in the standard interview were as follows: weight gain $>10 \mathrm{~kg}$ since 20 years of age (yes/no), change in body weight > $3 \mathrm{~kg}$ in 1 year (yes/no), and walking speed (faster walking speed compared with the same age and sex, yes/no).

\section{Exercise habits and physical activities}

The "Physical Activity reference for Health Promotion 2013" distinguishes between "exercise habits" for sports and physical fitness and those related to living, such as employment, housework, and mobility. ${ }^{28}$ The questionnaire items for the medical examination were set according to these criteria: exercise habit was defined by whether the individual lightly sweated and exercised for at least $30 \mathrm{~min}$ at least twice a week for more than 1 year. Physical activity was defined as walking for 1 or more hours per day or equivalent activity.

\section{Medical history}

Information regarding medical history, surgery, and subjective symptoms were collected via interviews with local public health nurses. A history of gastrointestinal surgery was defined as at least one occurrence of esophageal, stomach, duodenal, or colon surgery. A history of lifestyle-related disease was defined as a history of any of the following conditions: hypertension, dyslipidemia, diabetes, hepatic dysfunction, or renal dysfunction. Subjective symptoms over the past year were classified into three categories: none, one, or two or more.

\section{Evacuees}

There was no information regarding the individuals' evacuation status based on their residence area in the target municipalities. All residents in areas designated as evacuation areas were defined as evacuees, and those in the areas not designated as evacuation areas were non-evacuees.

\section{Statistical analysis}

We divided the participants into two groups: undernourished $(n=1712)$ and not undernourished $(n=13,019)$. Participants with and without undernutrition were compared using the chi-squared test for categorical variables and the $t$-test for continuous variables. We tested the associations between undernutrition after the disaster and other primary lifestyle factors using a simple, sex/age-adjusted, and multivariate-adjusted analysis through the Cox proportional hazard regression model. Although there were missing values for lifestyle factors, there was no difference in the mean age, BMI, sex distribution, malnutrition, 
evacuation, exercise habits, and physical activity, even when the missing values were excluded. We therefore treated these values as missing to ensure representativeness. We performed a univariate analysis after deleting the missing data; in the multivariate analysis, we made adjustments by inserting dummy variables into the missing data. In the multivariate-adjustment model, items that were associated in a statistically significant manner with undernutrition in the sex/age-adjustment model were employed as adjustment variables. To avoid multicollinearity of exercise habits and physical activity, one of the habits was employed as an adjustment variable if both were statistically significant in a sex/age-adjusted analysis. The follow-up period was defined as the period until the detection of the first case of undernutrition; in cases without undernutrition, the follow-up period was defined as the period until the final medical examination in 2017. We calculated the person-years as the sum of the individual follow-up times until the incidence of undernutrition or the last date of examination.

We employed SAS version 9.4 (SAS Institute, Cary, NC, USA) for all statistical analyses, with two-tailed probability values for the statistical tests. A p-value $\leq$ 0.05 was considered statistically significant.

\section{Ethical considerations}

The Ethics Committee of the Fukushima Medical University approved this study (\#1319, \#1916), and informed consent was obtained from the community representatives to conduct an epidemiologic study based on the guidelines of the Council for International Organizations of Medical Science.

\section{Results}

\section{Relationship between lifestyle factors and undernutrition Frequency and characteristics of undernutrition after the disaster}

Table 1 shows the baseline characteristics of the participants with and without undernutrition. Their mean age was $68.4 \pm 6.2$ years, and $46.6 \%$ were men. During the 6.9-year follow-up, 1712 (12.8\%) of the participants were undernourished and were significantly older, with a higher percentage of women and a lower percentage of evacuees. Compared with the participants without undernutrition, the frequency of meals before going to bed, exercise habits, physical activity, smoking habits, and alcohol consumption were lower among those with undernutrition. The proportion of lifestyle-related diseases was significantly higher among those with undernutrition than among those without undernutrition.

\section{Lifestyle factors associated with undernutrition}

Table 2 shows the sex/age-adjusted and multivariate-adjusted hazard ratios (HRs) and 95\% confidence intervals (Cls) for each lifestyle factor of undernutrition. The multivariate-adjusted model included the variables that were significantly associated with the sex/age-adjustment model. Exercise habits and physical activity were related to each other in the chi-squared test $\left(\chi^{2}, 2538.43, p<0.0001\right.$, phi coefficient 0.45$)$. Therefore, if both of these factors were statistically significant in the sex/age-adjustment analysis, only one of them was employed as an adjustment variable to avoid multicollinearity. The statistically significant variables influencing the onset of undernutrition in model 1 were as follows: non-evacuation ( $\mathrm{HR}, 1.31$; 95\% $\mathrm{Cl} 1.17-1.47)$, poor (< $30 \mathrm{~min} / 2$ times/week) exercise habits (HR, 1.14; 95\% Cl 1.03-1.27), no/infrequent meals before going to bed (HR, 1.26; 95\% Cl 1.11-1.43), history of gastrointestinal surgery (HR, 1.24; $95 \% \mathrm{Cl} 1.03-1.50)$, history of lifestyle-related disease (HR, 1.27; $95 \% \mathrm{Cl} 1.16-1.40)$, and two or more subjective symptoms (HR, 1.26; $95 \% \mathrm{Cl} 1.04-1.53$ ). The $\mathrm{HR}$ (and $95 \% \mathrm{Cl}$ ) of exercise habits was unchanged, even when the baseline BMls were added to the adjustment variable.

The variables that significantly influenced the onset of undernutrition in model 2 were as follows: non-evacuation ( $\mathrm{HR}, 1.31 ; 95 \% \mathrm{Cl} 1.17-1.47)$, poor () physical activity (HR, 1.14; 95\% Cl 1.01-1.25), no/infrequent meals before going to bed (HR, 1.25; 95\% $\mathrm{Cl} 1.01-1.42)$, history of gastrointestinal surgery (HR, $1.24 ; 95 \% \mathrm{Cl} 1.02-1.49)$, history of lifestyle-related disease (HR, 1.28; 95\% Cl 1.16-1.41), and two or more subjective symptoms (HR, 1.26; 95\% Cl 1.04-1.52). $\mathrm{HR}$ of physical activity (and $95 \% \mathrm{Cl}$ ) was not statistically significant when the baseline BMI was added to the adjustment variable.

Table 3 shows the HRs of exercise habits and physical activity to the incidence of undernutrition after the disaster in the multivariate-adjustment model, stratified by each lifestyle factor. From the results of this model stratified, no statistically significant interaction with exercise habits or physical activity was confirmed for each lifestyle factor.

\section{Discussion}

\section{Exercise habits and physical activities}

Inadequate exercise habits and physical activities affected the onset of undernutrition after the disaster in older adults. The HR of exercise habits was unchanged even when the baseline BMls were added to the adjustment variable. Exercise habits are an important preventive factor for undernutrition among older adults regardless of whether the baseline weight is high or low. No interaction with exercise habits was confirmed for any variable. Thus, to prevent undernutrition after a disaster, it is important for older adults in evacuated areas to maintain their exercise habits and physical activities, regardless of their sex, age, drinking and smoking status, and medical history.

Increasing the amount of daily physical activity can reduce the risk of age-related decline in life functions, such as decreased motor function and dementia. Older adults can live longer independently by following a physically active lifestyle. ${ }^{28}$ More physical activity and exercise can lower the risk of developing lifestyle-related diseases, cancer, and even death. ${ }^{29-31}$ Exercise habits are associated with improved quality of life in older adults ${ }^{32}$ and decreased risk of upper respiratory tract infection. ${ }^{33}$ In this study, we did not examine the changes in exercise habits and physical activity after the disaster. We therefore cannot provide conclusions regarding the effects of continuing exercise habits or physical activity on the onset of undernutrition. However, our study showed that 
regardless of the physical activity status after the disaster, being physically active before the disaster suppressed the prevalence of undernutrition after the disaster. Maintaining exercise habits and physical activity in daily life is important for older adults who are more vulnerable to disasters because these habits and activities would reduce their risk of impaired physical function and improve their quality of life. Frailty can be treated through interventions, such as improving their walking speed and increasing the amount of physical activity. ${ }^{34}$

\section{Association with evacuation}

The prevalence of undernutrition was low among the evacuees after the disaster. According to the FHMS, a large proportion of the people from the evacuation areas gained weight after the disaster. ${ }^{9}$ The study results indicate that, in the evacuation areas, even older adults gained weight. However, a certain number of people in the evacuation areas were undernourished. After the disaster, life in the shelters was prolonged, with meals that were high in carbohydrates. ${ }^{11}$ Living in non-house conditions after the disaster was associated with a poor dietary intake of fruits and vegetables, meat, and soybean and dairy products, ${ }^{15}$ with one study showing that individuals started consuming more calories and proteins. ${ }^{8}$ Thus, in an environment where the content and form of meals cannot be selected, the evacuees had to eat the available food, regardless of their nutritional balance. The evacuees were therefore likely to gain weight. However, for older adults with poor gastrointestinal or swallowing/chewing function, the nutritional intake might decrease in these circumstances. One of the problems was that the disaster management teams tended to focus on gaining weight and may have delayed their response to undernutrition. In situations such as disasters, it is important not to miss such cases of undernutrition.

\section{Late meals}

The tendency to eat meals before going to bed fewer than 3 times a week was a risk factor for undernutrition. Eating within $2 \mathrm{~h}$ of bedtime is, however, regarded as a dietary habit that promotes obesity owing to the fat accumulation that results from insulin secretion and action of the appetite hormone leptin. However, older people have a higher undernutrition risk and/or weight loss than their younger counterparts. Therefore, delaying dinner might help prevent undernutrition and weight loss. Nevertheless, going to bed immediately after a meal is not recommended for the long term because it degrades sleep quality and strains the gastrointestinal tract. Reviewing the dietary balance and lifestyle of older adults is therefore an important step.

\section{Study limitations}

First, high-risk undernourished adults tend to undergo medical treatment and are therefore less likely to attend health check-ups, resulting in the possibility of a selection bias. Comparing the characteristics of the 13,378 participants with the 4223 who could not be tracked showed that the age groups were significantly different, with a mean age of 68.4 versus 73.3 years. There was no difference in the distribution of sex, exercise habits, or physical activity. Second, the undernutrition in certain cases was attributable to other diseases (other than lifestyle diseases); however, we could not rule out those patients from our analysis, which might have affected the results. Third, this study employed items from health check-ups. There was therefore a lack of detailed information on nutrient intake, which is strongly associated with weight loss and undernutrition. Fourth, the estimated weight loss (a risk factor for older adults) was $3-5 \mathrm{~kg}$ or $5 \%$ reduction in body weight over the previous 6 months to 1 year, ${ }^{24}$ however, the follow-up period varied for the participants, making it difficult to determine when the weight loss occurred. Lastly, we examined the effects of exercise habits before the disaster (baseline) but did not assess the changes in exercise habits after the disaster. We therefore could not determine whether the continuation of exercise habits affected the onset of undernutrition.

\section{Conclusions And Implications}

We examined the associations between the prevalence of undernutrition and related lifestyle factors after the disaster using health check-up data for residents aged 60 years or more living in the evacuation areas before the disaster. To prevent undernutrition after any disaster, those affected need to maintain their exercise habits and physical activities, regardless of other lifestyle habits and sex.

\section{Declarations}

\section{Ethics approval and consent to participate}

The Ethics Committee of the Fukushima Medical University approved this study (\#1319, \#1916), and. informed consent was obtained from the community representatives to conduct an epidemiologic study based on the guidelines of the Council for International Organizations of Medical Science.

\section{Consent for publication}

Not applicable.

\section{Availability of data and materials}

The datasets analyzed during the current study are not publicly available because the data of the Fukushima Health Management Survey belongs to the government of Fukushima prefecture but are available from the corresponding author on reasonable request.

\section{Competing interests}

The authors declare that there are no competing interests.

\section{Funding}

This survey was supported by the National Health Fund for Children and Adults Affected by the Nuclear Incident for design and conduct of the study. 


\section{Acknowledgments}

We would like thank the expert committee members, advisors, staff of the Fukushima Health Survey Group, and municipalities in the evacuation area for conducting this survey and for their support. This study was supported by the National Health Fund for Children and Adults Affected by the Nuclear Incident. The findings and conclusions of this article are solely the authors' responsibility and do not represent the official views of the Fukushima Prefectural Government. All authors participated in study conception and design. T.O. F.H., and K.O. performed the statistical analysis of the data. All authors participated in the interpretation of the results, drafting of the manuscript, and approval of the final version.

\section{References}

1) Akiyama H, Concept of science and society in the age of longevity. Science journal "Kagaku” Iwanami Shoten, 2010; 80:59-64.

2) Xue QL, Bandeen-Roche K, Varadhan R, et al. Internal manifestations of frailty criteria and the development of frailty phenotype in the Women's Health and Aging Study II. J Gerontol A Biol Sci Med Sci 2008;63:984-990.

3) Ministry of Health, Labor and Welfare. Summary of the results of the 2017 National Health and Nutrition Survey. (2018.09.11) https://www.mhlw.go.jp/content/10904750/000351576.pdf.(2019.9.11)

4) Yasumura S, Abe M. Fukushima Health Management Survey and Related Issues. Asia Pacific J of Public Health 2017;29:29-35.

5) Okada N, Shirasawa M, Hashimoto T, et al. Current situation and issues of crisis management for older people requiring assistance and nursing care in the Niigata Chuetsu Earthquake. 2006.

6) Shimizu S, Tamamura K. The Elderly People and the Great East Japan Disaster of March 11, 2011. Bulletin of Nara University of Education (Humanities and Society) 2013;62:59-70

7) Tanba F. Current status and issues of evacuees in the accident at TEPCO's Fukushima Daiichi nuclear power plant. 32nd Atomic Energy Commission Document1-3.http://www.aec.go.jp/jicst/NC/iinkai/teirei/siryo2013/siryo32/siryo1-3.pdf.(2019.12.20)

8) Mihara M, Harada M, Oka J, Tsuboyama-Kasaoka N. The effect of lunch box provision and mass feeding on energy and nutrient supply at emergency shelters after the Great East Japan Earthquake. Japanese Journal of Public Health 2019;10: 629-637.

9) Ohira T, Hosoya M, Yasumura S, et al. Effect of evacuation on body weight after the Great East Japan Earthquake. Am J Prev Med 2016;50:553-560.

10) Ohira T, Hosoya M, Yasumura S, et al. Evacuation and risk of hypertension after the Great East Japan Earthquake: The Fukushima Health Management Survey. Hypertension 2016;68:558-564.

11) Satoh H, Ohira T, Hosoya M, et al. Evacuation after the Fukushima Daiichi Nuclear Power Plant Accident Is a Cause of Diabetes: Results from the Fukushima Health Management Survey. J Diabetes Res 2015;2015:627390.

12) Satoh $H$, Ohira $T$, Nagai $M$, et al. Hypo-high-density lipoprotein cholesterolemia caused by evacuation after the Fukushima Daiichi nuclear power plant accident: results from the Fukushima Health Management Survey. Intern Med 2016;55:1967-1976.

13) Hashimoto S, Nagai M, Fukuma S, et al. influence of post-disaster evacuation on incidence of metabolic syndrome. J Atheroscler Thromb 2017;24:327337.

14) Takahashi A, Ohira T, Hosoya M, et al. Effect of evacuation on liver function after the Fukushima Daiichi Nuclear Power Plant accident: The Fukushima Health Management Survey. J Epidemiol 2017;27:180-185.

15) Zhang W, Ohira T, Abe M, et al. Evacuation after the Great East Japan Earthquake was associated with poor dietary intake: The Fukushima Health Management Survey. J Epidemiol 2017;1:14-23.

16) Tsubota UM, Yonekura Y, Tanno K, et al. Association between health risks and frailty in relation to the degree of housing damage among elderly survivors of the great East Japan earthquake. BMC Geriatr 2018;133.

17) Shimada H, Makizako H, Doi T, et al. Combined prevalence of frailty and mild cognitive impairment in a population of elderly Japanese people. J Ame Med Dir Assoc 2013;14:518-524.

18) Kojima G, lliffe S, Yu T, et al. Prevalence of frailty in Japan: A systematic review and meta-analysis. J Epidemiol 2017;27:347-353.

19) Barbosa-Silva, M C囚Subjective and objective nutritional assessment methods: what do they really assess? Curr Opin Clin Nutr Metab Care 2008; 11:248254.

20) Sasazuki S, Inoue M, Tsuji I, er al. Body Mass Index and Mortality from All Causes and Major Causes in Japanese: Results of a Pooled Analysis of 7 LargeScale Cohort studies. J Epidemiol 2011;21:417-430. 
21) Yokoyama Y, Kitamura A, Kawano Y, et al. Dietary intake and nutritional status among Japanese elderly participants in the National Health Survey Japan 2003-2011. J Japanese Society of Shokuiku 2018; 12:33-40.

22) Cook Z, Kirk S, Lawrenson S, Sandford S. BAPEN Symposium 3 on 'From beginners to zimmers' Use of BMI in the assessment of undernutrition in older subjects: reflecting on practice. Proceedings of the Nutrition Society 2005; 64:313-317.

23) Dietary Intake and Nutritional Status among Japanese Elderly Participants in the National Health and Nutritional Survey Japan 2003-2011. Journal of the Japanese Society of Shokuiku 2018;12:33-40.

24) Japan Geriatrics Society: Statement of the Japan Geriatrics Society on frailty. (2014.5.13) https://www.jpn-geriatsoc.or.jp/info/topics/pdf/20140513_01_01.pdf. (2019.12.03)

25) Fried LP, Tangen CM, Walston J, et al. Frailty in older adults: Evidence for a phenotype. J Gerontol A Biol Sci Med Sci 2001;56:146-156.

26) Heidi G, Kathryn H. Unintentional weight loss in older adults. Am Fam Physician 2014;89:718-722.

27) Ministry of Health, Labor and Welfare. Health guidance program (revised version); Part 2 Medical Examination Attachment 3 Standard Questionnaire. 2013; 49-54.

28) Ministry of Health, Labor and Welfare 2013. Physical activity reference for health promotion 2013. https://www.mhlw.go.jp/content/000306883.pdf. (2020.01.10)

29) Hayashi T, Tsumura K, Suematsu C, et al. Walking to work and the risk for hypertension in men: the Osaka Health Survey. Ann Intern Med 1999;131:21-26.

30) Suzuki S, Kojima M, Tokudome S, et al. Effect of physical activity on breast cancer risk: findings of the Japan collaborative cohort study. Cancer Epidemiol Biomarkers Prev 2008;17:3396-3401.

31) Takahashi H, Kuriyama S, Tsubono Y, et al. Time spent walking and risk of colorectal cancer in Japan: the Miyagi Cohort study. Eur J Cancer Prev 2007;16:403-408.

32) Rosenbaum S, Sherrington C. Is exercise effective in promoting mental well-being in older age? A systematic review. Br J Sports Med 2011;45:1079-1080.

33) Martin SA, Pence BD, Woods JA. Exercise and respiratory tract viral infections. Exerc Sport Sci Rev 2009;37:157-164.

34) Cameron ID, Fairhall N, Langron C, et al. A multifactorial interdisciplinary intervention reduces frailty in older people: randomized trial. BMC Med 2013;11:65.

\section{Tables}




\begin{tabular}{|c|c|c|c|c|c|c|c|c|c|}
\hline \multirow[b]{2}{*}{ Participants } & & \multirow[b]{2}{*}{$\mathrm{n}$} & \multirow{2}{*}{$\begin{array}{l}\text { Total } \\
13,378\end{array}$} & & \multicolumn{2}{|c|}{ Undernutrition } & \multicolumn{2}{|c|}{$\begin{array}{l}\text { non- } \\
\text { Undernutrition }\end{array}$} & \multirow[t]{2}{*}{$\begin{array}{l}\mathrm{p} \\
\text { values* }\end{array}$} \\
\hline & & & & & 1,712 & $(12.8)$ & 11,666 & $(87.2)$ & \\
\hline Follow-up period, (years) & & 13,378 & 6.9 & $(2.2)$ & 4.9 & $(2.0)$ & 7.2 & $(2.1)$ & $<0.001$ \\
\hline Evacuee, (\%) & & 13,378 & 3,732 & $(27.9)$ & 411 & $(24.0)$ & 3,321 & $(28.5)$ & $<0.001$ \\
\hline Sex(men), n(\%) & & 13,378 & 6,351 & $(47.5)$ & 631 & $(36.9)$ & 5,720 & $(51.0)$ & $<0.001$ \\
\hline Age, (years) & & 13,378 & 68.4 & $(6.2)$ & 68.8 & $(6.3)$ & 68.3 & $(6.2)$ & 0.003 \\
\hline 75 years old or older, n (\%) & & 13,378 & 2,796 & $(20.9)$ & 389 & $(22.7)$ & 2,407 & $(20.6)$ & 0.047 \\
\hline 80 years old or older, n (\%) & & 13,378 & 659 & $(4.9)$ & 99 & $(5.8)$ & 560 & $(4.8)$ & 0.08 \\
\hline Body weight, (kg) & & 13,378 & 54.7 & $(6.8)$ & 50.7 & $(6.0)$ & 55.2 & $(6.7)$ & $<0.001$ \\
\hline Body mass index, $(\mathrm{kg} / \mathrm{m} 2)$ & & 13,378 & 22.7 & $(1.3)$ & 21.3 & $(1.0)$ & 22.9 & $(1.3)$ & $<0.001$ \\
\hline Amount of Weight loss, (kg) & & 13,378 & 0.53 & $(3.8)$ & 4.65 & $(3.0)$ & -0.07 & $(3.5)$ & $<0.001$ \\
\hline Rate of Weight loss, (\%) & & 13,378 & 1.01 & $(7.0)$ & 9.02 & $(5.4)$ & -0.16 & $(6.4)$ & $<0.001$ \\
\hline Rate of Weight loss, (kg/year) & & 13,378 & 0.12 & $(0.7)$ & 1.05 & $(0.8)$ & -0.02 & $(0.6)$ & $<0.001$ \\
\hline Rate of Weight loss, (\%/year) & & 13,378 & 0.22 & $(1.4)$ & 2.06 & $(1.6)$ & -0.05 & $(1.1)$ & $<0.001$ \\
\hline Weight loss $\geq 5 \mathrm{~kg}, \mathrm{n}(\%)$ & & 13,378 & 1,422 & $(10.6)$ & 645 & $(37.7)$ & 777 & $(6.7)$ & $<0.001$ \\
\hline Weight loss $\geq 5 \%$, n (\%) & & 13,378 & 3,560 & $(26.6)$ & 1,268 & $(74.1)$ & 2,292 & $(19.7)$ & $<0.001$ \\
\hline Exercise habits, n (\%) & <30min/2times/week & 12,488 & 8,061 & $(64.6)$ & 1,065 & $(67.0)$ & 6,996 & $(64.2)$ & 0.03 \\
\hline Physical activities, n (\%) & $<1$ hour/day & 12,495 & 7,556 & $(60.5)$ & 1,010 & $(63.5)$ & 6,546 & $(60.0)$ & 0.01 \\
\hline Walking speed, n (\%) & fast & 12,490 & 5,543 & $(44.4)$ & 693 & $(43.6)$ & 4,850 & $(44.5)$ & 0.51 \\
\hline Insufficient sleep, n (\%) & yes & 12,532 & 9,768 & $(77.9)$ & 1,212 & $(76.1)$ & 8,556 & $(78.2)$ & 0.06 \\
\hline Weight change from age $20, \mathrm{n}(\%)$ & $\geq 10 \mathrm{~kg}$ & 12,493 & 2,760 & $(22.1)$ & 161 & $(10.1)$ & 2,599 & $(23.8)$ & $<0.001$ \\
\hline Weight change in 1year, $\mathrm{n}(\%)$ & $\geq \pm 3 \mathrm{~kg}$ & 12,492 & 2,055 & $(16.5)$ & 201 & $(12.7)$ & 1,854 & $(17.0)$ & $<0.001$ \\
\hline Meals before going to bed, $\mathrm{n}(\%)$ & $\geq 3$ times/week & 12,498 & 2,835 & $(22.7)$ & 294 & $(18.5)$ & 2,541 & $(23.3)$ & $<0.001$ \\
\hline Snack after dinner, n (\%) & $\geq 3$ times/week & 12,514 & 913 & (7.3) & 116 & $(7.3)$ & 797 & (7.3) & 0.98 \\
\hline Lack of breakfast, n (\%) & $\geq 3$ times/week & 12,502 & 445 & $(3.6)$ & 60 & (3.8) & 385 & $(3.5)$ & 0.61 \\
\hline Smoking status, n (\%) & Current smoker & 13,378 & 1,762 & $(13.2)$ & 194 & $(11.3)$ & 1,568 & $(13.4)$ & 0.02 \\
\hline \multirow[t]{3}{*}{ Drinking status, n (\%) } & Non drinker & 13,378 & 7,553 & $(56.5)$ & 1,098 & $(64.1)$ & 6,455 & $(55.3)$ & $<0.001$ \\
\hline & \multicolumn{2}{|l|}{ Current drinker, $<44 \mathrm{~g} /$ day } & 5,164 & $(38.6)$ & 547 & $(32.0)$ & 4,617 & $(39.6)$ & \\
\hline & \multicolumn{2}{|c|}{ Current drinker, $\geq 44 \mathrm{~g} /$ day } & 661 & $(4.9)$ & 67 & $(3.9)$ & 594 & $(5.1)$ & \\
\hline Digestive surgery, n (\%) & yes & 13,378 & 821 & $(6.1)$ & 120 & $(7.0)$ & 701 & $(6.0)$ & 0.11 \\
\hline Lifestyle-related diseases, n (\%) & yes & 13,378 & 5,586 & $(41.8)$ & 797 & $(46.6)$ & 4,789 & $(41.1)$ & $<0.001$ \\
\hline \multirow[t]{3}{*}{ Subjective symptoms, n (\%) } & nothing & 13,378 & 10,543 & $(78.8)$ & 1,339 & $(78.2)$ & 9,204 & $(78.9)$ & 0.04 \\
\hline & \multicolumn{2}{|l|}{1 symptom } & 2,077 & $(15.5)$ & 254 & $(14.8)$ & 1,823 & $(15.6)$ & \\
\hline & \multicolumn{2}{|l|}{2 or more } & 758 & $(5.7)$ & 119 & $(7.0)$ & 639 & $(5.5)$ & \\
\hline
\end{tabular}




\begin{tabular}{|c|c|c|c|c|c|c|c|c|c|c|c|c|c|}
\hline \multirow{3}{*}{$\begin{array}{l}\text { Factor } \\
\text { Sex (Women) }\end{array}$} & \multirow{3}{*}{$\begin{array}{l}\text { reference } \\
\text { men }\end{array}$} & \multicolumn{4}{|c|}{ Sex-Age- adjustment } & \multicolumn{4}{|c|}{$\begin{array}{l}\text { Multivariable adjustment } \\
\text { (Model1)* }\end{array}$} & \multicolumn{4}{|c|}{ 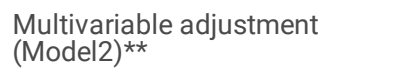 } \\
\hline & & \multicolumn{3}{|c|}{$\mathrm{HR}(95 \% \mathrm{Cl})$} & \multirow{2}{*}{$\begin{array}{l}\mathrm{p} \\
\text { values } \\
<0.001\end{array}$} & \multicolumn{3}{|c|}{$\mathrm{HR}(95 \% \mathrm{Cl})$} & \multirow{2}{*}{$\begin{array}{l}\mathrm{p} \\
\text { values } \\
<0.001\end{array}$} & \multicolumn{3}{|c|}{$\mathrm{HR}(95 \% \mathrm{Cl})$} & \multirow{2}{*}{$\begin{array}{l}\mathrm{p} \\
\text { values } \\
<0.001\end{array}$} \\
\hline & & 1.63 & $(1.48-$ & $1.80)$ & & 1.64 & $(1.45-$ & 1.85) & & 1.63 & $(1.44-$ & 1.84) & \\
\hline Age & 1SD (6.2 years) & 1.24 & $(1.18-$ & 1.31) & $<0.001$ & 1.25 & $(1.18-$ & 1.32) & $<0.001$ & 1.24 & $(1.18-$ & 1.31) & $<0.001$ \\
\hline Age ( $\geq 75$ years old) & $<75 y e a r s$ old & 1.60 & $(1.43-$ & $1.79)$ & $<0.001$ & & & & & & & & \\
\hline Age ( $\geq 80$ years old) & $<80$ years old & 1.96 & $(1.60-$ & $2.41)$ & $<0.001$ & & & & & & & & \\
\hline Evacuation (no) & yes & 1.36 & $(1.21-$ & $1.52)$ & $<0.001$ & 1.31 & $(1.17-$ & 1.47) & $<0.001$ & 1.31 & $(1.17-$ & 1.47) & $<0.001$ \\
\hline Walking speed (fast) & slow & 0.94 & $(0.85-$ & $1.03)$ & 0.18 & & & & & & & & \\
\hline Insufficient sleep (yes) & no & 1.11 & $(0.99-$ & $1.25)$ & 0.08 & & & & & & & & \\
\hline $\begin{array}{l}\text { Exercise habits } \\
(<30 \mathrm{~min} / 2 \text { times/week })\end{array}$ & $\geq 30 \mathrm{~min} / 2$ times/week & 1.16 & $(1.04-$ & 1.29) & 0.006 & 1.14 & $(1.03-$ & 1.27) & 0.02 & & & & \\
\hline $\begin{array}{l}\text { Physical activities } \\
(<1 \text { hour/day) }\end{array}$ & $\geq 1$ hour/day & 1.15 & $(1.04-$ & 1.27) & 0.009 & & & & & 1.12 & $(1.01-$ & $1.25)$ & 0.03 \\
\hline Smoking status (yes) & no & 1.20 & $(1.02-$ & 1.41) & 0.03 & 1.16 & $(0.99-$ & 1.37) & 0.07 & 1.16 & $(0.99-$ & 1.37) & 0.07 \\
\hline $\begin{array}{l}\text { Drinking status }(< \\
44 \mathrm{~g} / \text { day })\end{array}$ & non-drinker & 0.87 & $(0.77-$ & $0.97)$ & 0.02 & 0.89 & $(0.79-$ & $1.00)$ & 0.05 & 0.89 & $(0.79-$ & $1.00)$ & 0.04 \\
\hline ( $\geq 44 \mathrm{~g} /$ day) & non-drinker & 1.03 & $(0.79-$ & 1.34) & 0.86 & 1.07 & $(0.82-$ & 1.39) & 0.64 & 1.06 & $(0.81-$ & 1.39) & 0.66 \\
\hline $\begin{array}{l}\text { Meals before going to } \\
\text { bed (<3times/week) }\end{array}$ & $\geq 3$ times/week & 1.27 & $(1.12-$ & 1.44) & $<0.001$ & 1.26 & $(1.11-$ & 1.43) & 0.03 & 1.25 & $(1.10-$ & 1.42) & $<0.001$ \\
\hline $\begin{array}{l}\text { Snack after dinner ( } \geq \\
3 \text { time/week) }\end{array}$ & $<3$ times/week & 1.01 & $(0.84-$ & $1.22)$ & 0.90 & & & & & & & & \\
\hline Digestive surgery (yes) & no & 1.27 & $(1.05-$ & 1.53) & 0.01 & 1.24 & $(1.03-$ & $1.50)$ & 0.02 & 1.24 & $(1.02-$ & 1.49) & 0.03 \\
\hline $\begin{array}{l}\text { Lifestyle-related } \\
\text { diseases (yes) }\end{array}$ & no & 1.29 & (1.17- & 1.42) & $<0.001$ & 1.27 & $(1.16-$ & 1.40) & $<0.001$ & 1.28 & $(1.16-$ & 1.41) & $<0.001$ \\
\hline $\begin{array}{l}\text { Subjective symptoms } \\
\text { (1 symptom) }\end{array}$ & no symptom & 0.96 & $(0.84-$ & 1.10) & 0.54 & 0.98 & $(0.86-$ & 1.13) & 0.80 & 0.98 & $(0.86-$ & 1.13) & 0.80 \\
\hline (2 or more) & no symptom & 1.25 & $(1.04-$ & $1.51)$ & 0.02 & 1.26 & $(1.04-$ & 1.53) & 0.02 & 1.26 & $(1.04-$ & 1.52) & 0.02 \\
\hline \multicolumn{14}{|c|}{$\begin{array}{l}\text { HR; Hazard ratio. Cl; confidence interval. SD; } \\
\text { standard deviation }\end{array}$} \\
\hline \multicolumn{14}{|c|}{$\begin{array}{l}\text { Dependent variable: Undernutrition. Independent variable of interest: } \\
\text { Exercise habits or Physical activity. }\end{array}$} \\
\hline \multicolumn{14}{|c|}{$\begin{array}{l}\text { * Model1 : Adjustment variables included in the model: Age, Sex, Evacuation, Exercise habits, Smoking status, Drinking status, Meals before going to bed, } \\
\text { Digestive surgery, Lifestyle-related diseases, and Subjective symptoms. }\end{array}$} \\
\hline
\end{tabular}




\begin{tabular}{|c|c|c|c|c|c|c|c|c|c|c|c|c|}
\hline & & \multicolumn{6}{|l|}{ Exercise habit } & \multicolumn{5}{|c|}{ Physical activity } \\
\hline & & $\begin{array}{l}\geq 30 \mathrm{~min} \\
/ 2 \text { times/week }\end{array}$ & & \multicolumn{4}{|c|}{$<30 \mathrm{~min} / 2$ times/week } & $\geq 1$ hour/day & & \multicolumn{3}{|c|}{$<1$ hour/day } \\
\hline \multicolumn{2}{|c|}{ Number of participants } & 4,427 & 8,061 & & & & & 4,939 & 7,556 & & & \\
\hline \multicolumn{2}{|l|}{$\begin{array}{l}\text { Number of } \\
\text { undernutrition }\end{array}$} & 525 & 1,065 & & & & & 580 & 1,010 & & & \\
\hline \multicolumn{2}{|l|}{$\begin{array}{l}\text { follow-up } \\
\text { years }\end{array}$} & 7.09 & 6.98 & & & & & 7.02 & 7.01 & & & \\
\hline \multicolumn{2}{|l|}{$\begin{array}{l}\text { Total person- } \\
\text { years }\end{array}$} & 31,381 & \multicolumn{5}{|c|}{56,249} & 34,678 & \multicolumn{4}{|c|}{53,004} \\
\hline \multicolumn{2}{|c|}{$\begin{array}{l}\text { Incidence rate of } \\
\text { undernutrition } \\
(1,000 \text { person-years) }\end{array}$} & 16.7 & \multicolumn{5}{|l|}{18.9} & 16.7 & \multicolumn{3}{|l|}{19.1} & \\
\hline & & & \multicolumn{3}{|c|}{$\mathrm{HR}(95 \% \mathrm{Cl})$} & $\begin{array}{l}\mathrm{p} \\
\text { values*1 }\end{array}$ & \multicolumn{2}{|l|}{$\begin{array}{l}\text { p for } \\
\text { interaction }\end{array}$} & \multicolumn{3}{|c|}{$\mathrm{HR}(95 \% \mathrm{Cl})$} & $\begin{array}{l}\mathrm{p} \\
\text { values*2 }\end{array}$ \\
\hline \multirow[t]{2}{*}{ Sex } & men & Reference & 1.21 & $(1.02-$ & $1.44)$ & 0.03 & \multirow[t]{2}{*}{0.49} & Reference & 1.08 & $(0.92-$ & $1.28)$ & 0.34 \\
\hline & women & Reference & 1.10 & $(0.96-$ & $1.25)$ & 0.18 & & Reference & 1.15 & $(1.01-$ & 1.31) & 0.04 \\
\hline \multirow[t]{2}{*}{ Age group } & $\begin{array}{l}\geq 75 \text { years } \\
\text { old }\end{array}$ & Reference & 0.93 & $(0.73-$ & 1.19) & 0.56 & \multirow[t]{2}{*}{0.54} & Reference & 1.00 & $(0.78-$ & 1.27) & 0.97 \\
\hline & $<75$ years old & Reference & 1.18 & $(1.05-$ & 1.33) & 0.005 & & Reference & 1.15 & $(1.02-$ & 1.29) & 0.02 \\
\hline \multirow[t]{2}{*}{ Evacuation } & no & Reference & 1.19 & $(1.05-$ & $1.35)$ & 0.007 & \multirow[t]{2}{*}{0.26} & Reference & 1.10 & $(0.97-$ & $1.24)$ & 0.13 \\
\hline & yes & Reference & 1.02 & $(0.85-$ & $1.24)$ & 0.81 & & Reference & 1.18 & (0.98- & 1.43) & 0.09 \\
\hline \multirow{2}{*}{$\begin{array}{l}\text { Smoking } \\
\text { status }\end{array}$} & no & Reference & 1.10 & $(0.98-$ & 1.23) & 0.09 & \multirow[t]{2}{*}{0.08} & Reference & 1.14 & $(1.02-$ & 1.27) & 0.02 \\
\hline & yes & Reference & 1.54 & $(1.10-$ & 2.14) & 0.01 & & Reference & 0.98 & (0.73- & 1.32) & 0.90 \\
\hline \multirow{3}{*}{$\begin{array}{l}\text { Drinking } \\
\text { status }\end{array}$} & no drinker & Reference & 1.09 & $(0.95-$ & 1.24) & 0.22 & & Reference & 1.19 & (1.05- & 1.36) & 0.01 \\
\hline & $<44 \mathrm{~g} /$ day & Reference & 1.22 & $(1.02-$ & 1.46) & 0.03 & 0.36 & Reference & 1.04 & (0.87- & 1.25) & 0.65 \\
\hline & $\geq 44 \mathrm{~g} /$ day & Reference & 1.46 & $(0.84-$ & 2.54) & 0.18 & 0.40 & Reference & 0.98 & $(0.59-$ & 1.62) & 0.93 \\
\hline \multirow{2}{*}{$\begin{array}{l}\text { Meals before } \\
\text { going } \\
\text { to bed }\end{array}$} & 3times/week & Reference & 1.16 & $(0.90-$ & 1.47) & 0.25 & \multirow[t]{2}{*}{0.94} & Reference & 1.19 & (0.94- & 1.51) & 0.15 \\
\hline & $\underset{\text { 3times/week }}{\geq}$ & Reference & 1.14 & $(1.02-$ & $1.28)$ & 0.03 & & Reference & 1.11 & $(0.99-$ & 1.25) & 0.07 \\
\hline \multirow{2}{*}{$\begin{array}{l}\text { Digestive } \\
\text { surgery }\end{array}$} & no & Reference & 1.12 & $(1.00-$ & $1.25)$ & 0.05 & \multirow[t]{2}{*}{0.19} & Reference & 1.12 & $(1.01-$ & $1.25)$ & 0.04 \\
\hline & yes & Reference & 1.53 & $(1.02-$ & 2.27) & 0.04 & & Reference & 1.14 & (0.78- & 1.67) & 0.49 \\
\hline Lifestyle- & no & Reference & 1.07 & $(0.92-$ & 1.23) & 0.02 & 0.20 & Reference & 1.06 & $(0.92-$ & 1.22) & 0.39 \\
\hline & yes & Reference & 1.24 & $(1.06-$ & $1.45)$ & 0.01 & & Reference & 1.20 & (1.03- & $1.40)$ & 0.02 \\
\hline Subjective & nothing & Reference & 1.14 & $(1.02-$ & 1.29) & 0.03 & & Reference & 1.16 & (1.03- & $1.30)$ & 0.01 \\
\hline & 1 symptom & Reference & 1.04 & $(0.78-$ & 1.37) & 0.81 & 0.46 & Reference & 0.94 & $(0.72-$ & $1.20)$ & 0.66 \\
\hline & 2 or more & Reference & 1.37 & $(0.87-$ & $2.16)$ & 0.17 & 0.45 & Reference & 1.12 & $(0.73-$ & 1.71) & 0.61 \\
\hline
\end{tabular}

HR; Hazard ratio. Cl; confidence interval.

*1 Adjustment variables included in the model: Age, Sex, Evacuation, Exercise habits, Smoking status, Drinking status, Meals before going to bed, Digestive Lifestyle-related diseases, and Subjective symptoms.

*2 Adjustment variables included in the model: Age, Sex, Evacuation, Physical activity, Smoking status, Drinking status, Meals before going to bed, Digestiv Lifestyle-related diseases, and Subjective symptoms. 


\section{Figures}
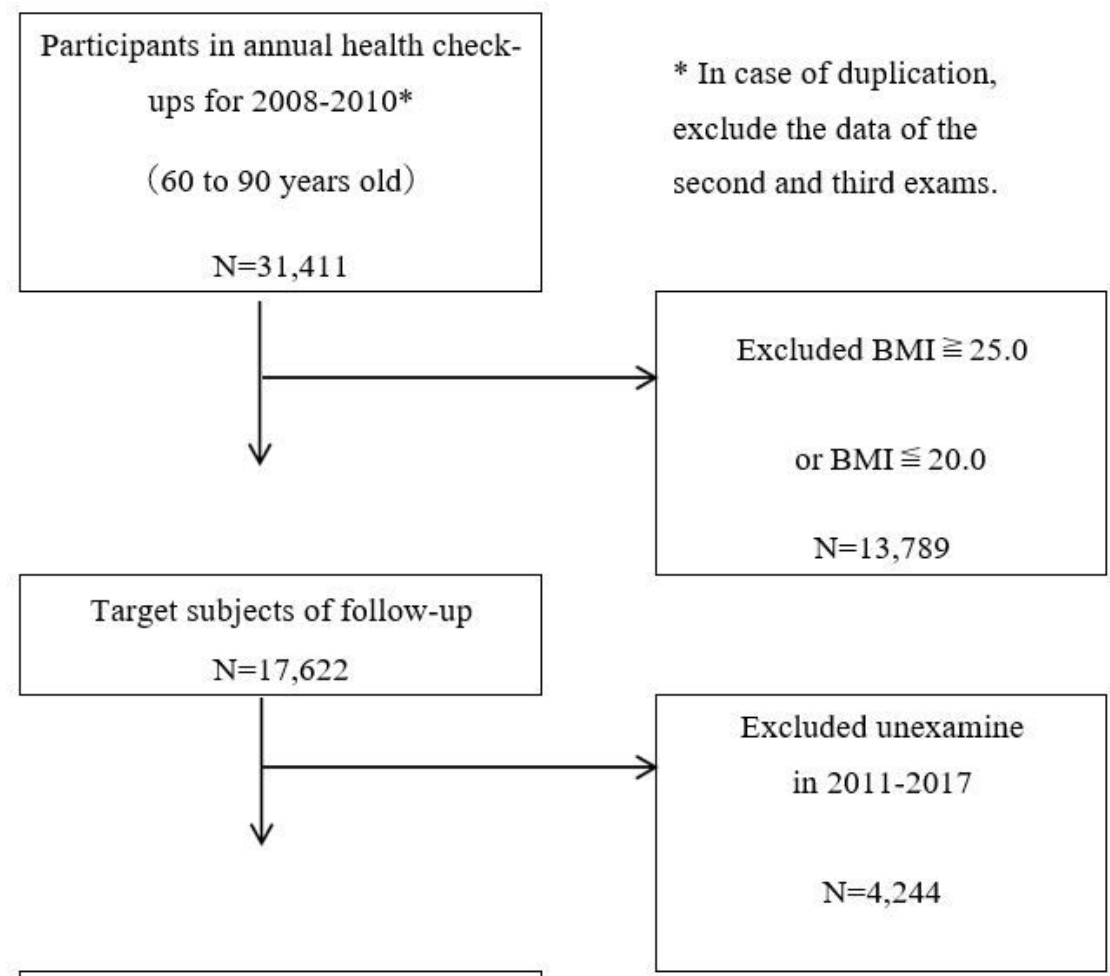

\begin{tabular}{|c|}
\hline $\begin{array}{l}\text { Subjects of analysis } \\
\qquad N=13,378\end{array}$ \\
\hline Mean follow-up period : 6.9years \\
\hline Follow-up rate $: 76.0 \%$ \\
\hline
\end{tabular}

\section{Figure 1}

Selection process for the study patients 

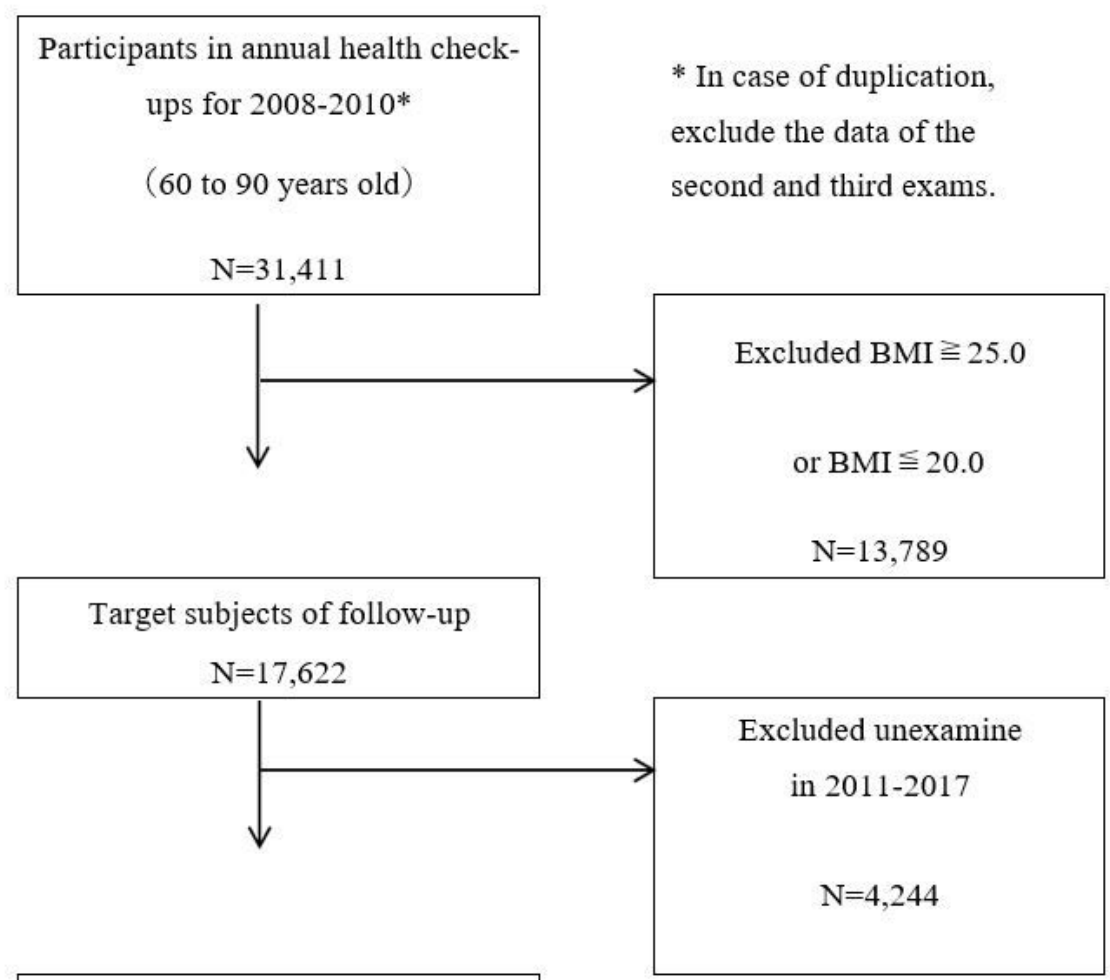

Subjects of analysis $\mathrm{N}=13,378$

Mean follow-up period : 6.9years

Follow-up rate : $76.0 \%$

Figure 1

Selection process for the study patients 

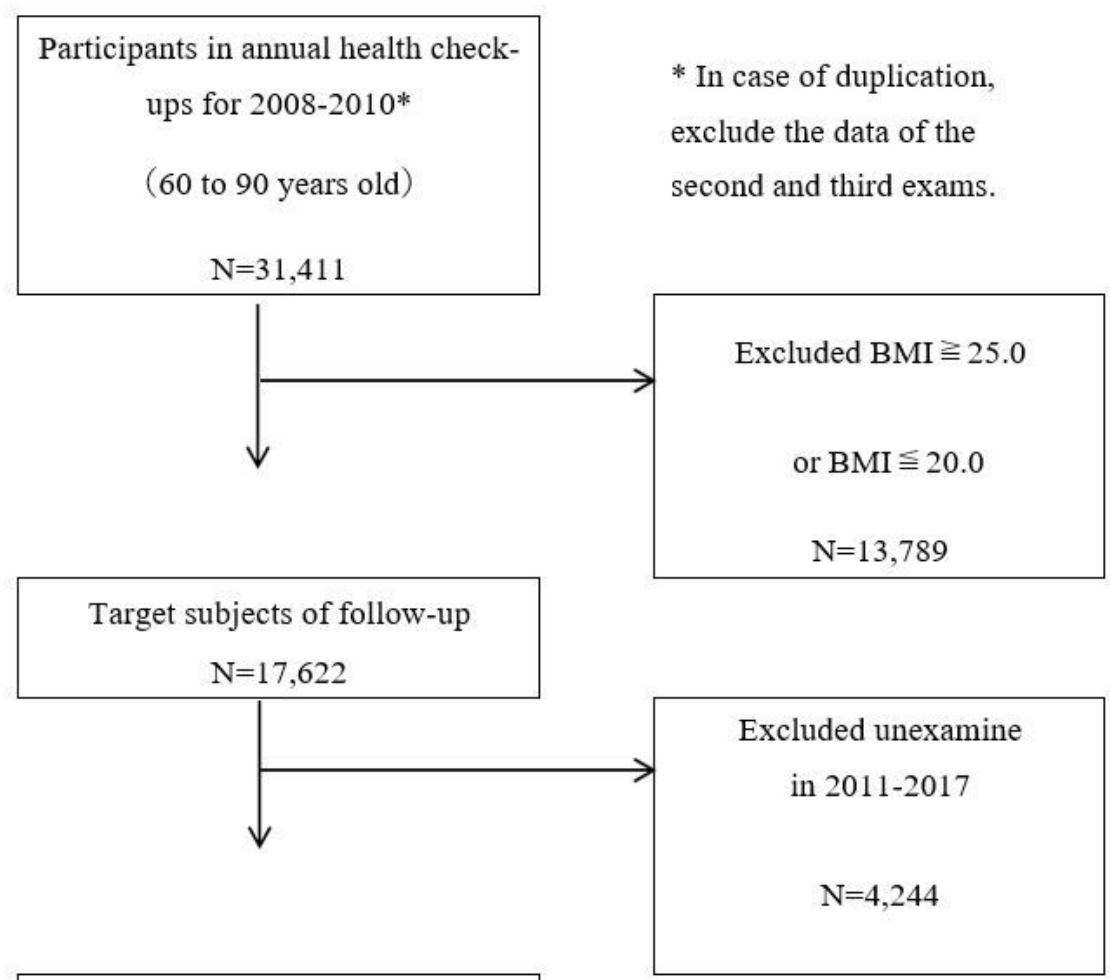

Subjects of analysis $\mathrm{N}=13,378$

Mean follow-up period : 6.9years

Follow-up rate : $76.0 \%$

Figure 1

Selection process for the study patients 

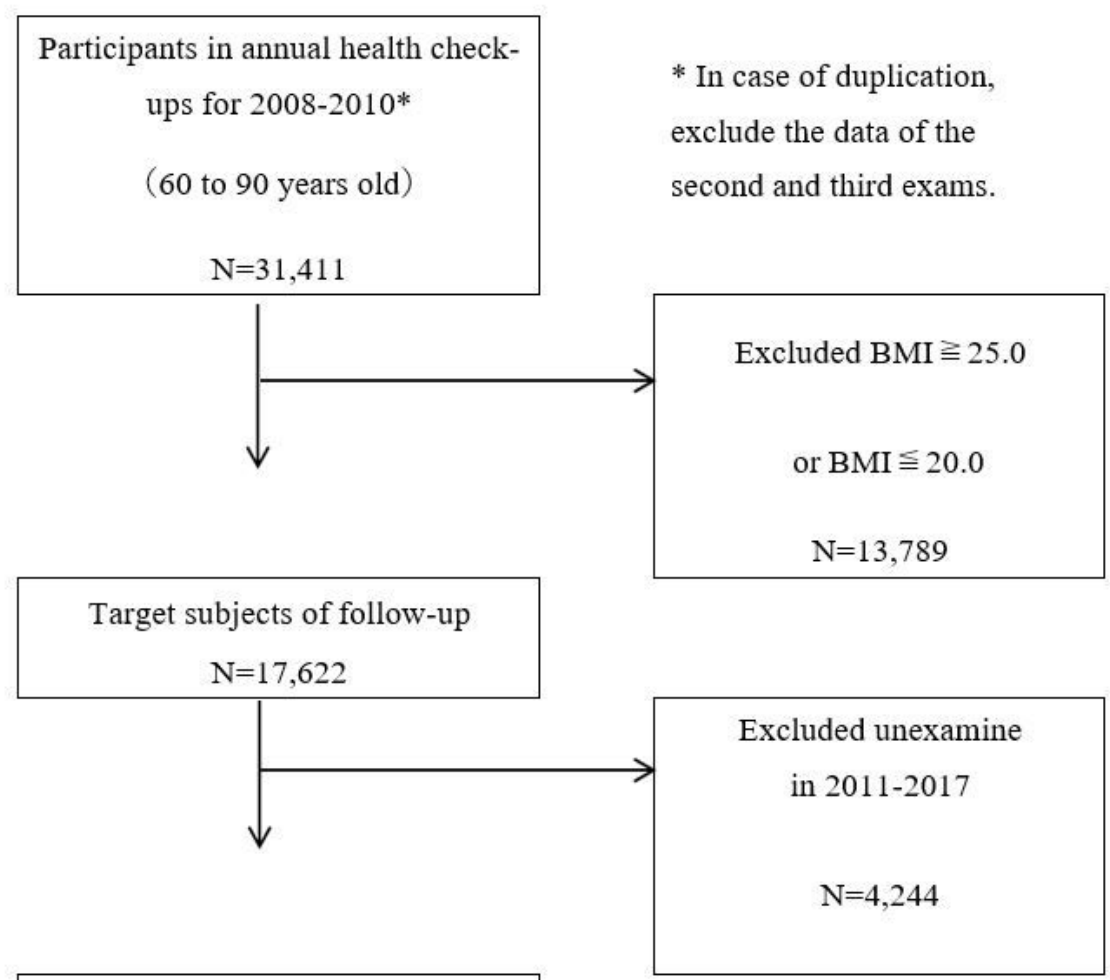

Subjects of analysis $\mathrm{N}=13,378$

Mean follow-up period : 6.9years

Follow-up rate : $76.0 \%$

Figure 1

Selection process for the study patients 